\title{
CAMILO RESTREPO, UN CINEASTA DEL DISENSO
}

\section{CAMILO RESTREPO, A FILMMAKER OF DISSENT}

DOI: $10.25100 /$ nc.v0vi27. 10569

Diana Kuéllar ${ }^{1}$

Universidad del Valle, Cali, Colombia

diana.cuellar@correounivalle.edu.co

ORCID: 0000-0003-4241-3500

Recibido: 16 de abril de 2020

Aprobado: 1 de junio de 2020

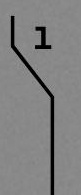


Resumen: la siguiente entrevista está extractada de un trabajo de investigación que aborda la relación entre violencia y documental en Colombia y busca responder a la pregunta ¿cómo se logra dislocar el consenso público y construir una memoria disidente que sobreviva a la saturación de discursos que circulan en torno a la violencia en Colombia? En la investigación mencionada se analizó el trabajo de algunos directores representativos de esta línea, entre ellos, Camilo Restrepo. La obra de Restrepo propone una gama de narrativas y estéticas híbridas muy personales, en un relato que intenta crear criterios estético-políticos no convencionales sobre la violencia de Colombia de los últimos años.

Palabras clave: Documental del disenso, Cineastas de la diáspora, Colombia.

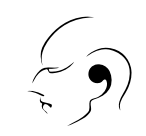

\begin{abstract}
: the following interview is the product of a research work about violence and documentary in Colombia, and that sought to answer the question: how is it possible to dislocate the public consensus and build a dissident memory that survives the saturation of discourses that circulate around violence in Colombia? For this, in this proposal was analysed some representative directors, among them was Camilo Restrepo. A recent director whose work proposes a range of narratives and hybrid aesthetics that maintain certain cohesion in a story that tries to create unconventional aesthetic-political criteria of the violence in Colombia in recent years.
\end{abstract}

Keywords: Documentary of dissent, Diaspora filmmakers, Colombia.

Esta entrevista hace parte de la tesis doctoral Documental del disenso: representación de la violencia contemporánea en Colombia, de la docente Diana Kuéllar. Universidad Carlos III de Madrid. Diciembre 2019. 
Camilo Restrepo (Medellín - 1975) es un artista plástico que desde los 22 años vive en París. En su búsqueda obstinada por lograr la conjunción entre lo representativo y lo abstracto, quimera utópica de la pintura, se produce su encuentro con el cine.

A Camilo Restrepo no lo conozco en persona, aunque me resulta cercano; una de sus películas formó parte del corpus de mi tesis doctoral. Tras ser puestos en contacto por mi director de tesis, Josexo Cerdán, entre el 2016 y el 2018 tuvimos un intercambio de correos electrónicos en el que yo indagaba sobre su vida y obra. Más que preguntas concretas yo le lanzaba detonantes y él, entusiasta, respondía. La siguiente entrevista es el resultado de esa relación epistolar. Hace poco nos escribimos a propósito de la terminación de mi tesis y de su última película, que aún no he visto. Restrepo me adelantó: "vas a encontrar en Los Conductos (2020) lazos estrechos con ideas tuyas. El capítulo de tu tesis llamado Medellín :"ciudad estallada”es totalmente la película. Entra en resonancia con otros temas que mencionás: limpieza social; la impresión (inscripción en el arma de Desquite, el bandido de los años 1950); lectura transversal de la historia (con la aparición en presente del bandido del pasado). Mágicamente, tu tesis termina hablando de Conductos".

Cuando empezamos a charlar, el cineasta había realizado tres cortos documentales que abordaban la realidad colombiana: Tropic Poket (2011), Como crece la sombra cuando el sol declina (2014) y La impresión de una guerra (2015). Esta última fue el objeto de mi investigación. En sus películas posteriores, Cilaos (2016) y La bouche (2017), aunque persisten ciertas temáticas y abordajes estéticos, cambia de territorio de trabajo y se concentra en su entorno inmediato, Paris. Tras ganar en el festival de cine de Locarno (2016) y estrenar en Cannes (2017), su nombre comienza a tomar notoriedad en Europa. En febrero de este año, 2020, recibe el galardón a Mejor Ópera Prima en la Berlinale con su largometraje "Los Conductos", producido por Felipe Guerrero, de Mutokino, y Helen Olive y Martin Bertier, de 5à7 Films.

Varios años después de abandonar los pinceles, en uno de sus viajes a Colombia, Restrepo decide probar otros puntos de vista y descubre, según sus palabras, que con el cine podía hacer potentemente lo que antes lo ponía en jaque en la pintura: trabajar, gracias al montaje, la implicación simbólica del punto de vista, la ilusión del espacio y el artificio de la representación. Estos elementos, sumados a las posibilidades plásticas del celuloide, con sus capas de color y emulsiones sensibles a la luz, que permiten trabajarlo como si fuera una superficie pictórica, le conducen al encuentro de la buscada perspectiva sin necesidad de tener una dirección figurativa. Es así como el celuloide se convierte en el soporte apropiado para exponer su lectura del mundo, con una propuesta que se aparta del cine hegemónico. 
El haber nacido y crecido en la ciudad de Medellín, durante uno de los periodos más brutales de la historia de Colombia, y luego haber emigrado a Europa, son improntas que impulsan a Restrepo a emprender una búsqueda personal para entender la realidad de su país a través del cine. El artista se aventura a explorar nuevos horizontes creativos partiendo de lo documental. Es gracias al manejo de un amplio espectro de recursos que logra componer su particular relato crítico. Sus películas, según el mismo director, fueron hechas para procesar por sus propios medios el desarraigo y entender la sociedad en la que nació y creció:

Nosotros, los colombianos, probablemente aún no hemos alcanzado suficiente desapego como para analizar una situación que todavía nos está agrediendo. La guerra en Colombia aún no ha terminado, y la violencia, menos. Todo lo que podemos aportar a esta primera etapa de análisis de nuestra historia reciente son nuestras propias historias, nuestras propias impresiones. (Kuéllar, 2019, p.233)

Las películas de Restrepo de este periodo inicial, al igual que las de los cineastas de la diáspora, plantean el regreso al lugar de origen y utilizan métodos subjetivos para cuestionar su propia representación de la realidad. Sus estrategias operan desde la emancipación del orden establecido en lo estético, lo político y en la representación. Son documentales del disenso "que proponen un cambio de paradigma desde un giro subjetivo y conceptual, creando espacios de resistencia no configurados en las grietas que existen entre el poder y la oposición” (Kuéllar, 2019, p.1). La localización de estas fracturas permite comprender la emergencia de un documental del disenso complejo y deja planteados aspectos no resueltos sobre los flujos de discernimiento presentes en estas representaciones.

Restrepo construye un relato que se vincula con una poética realista, al presentar la violencia desde su faceta "más íntima” y, tal vez, omitida. Ante la fragilidad de la memoria y su inevitable evaporación en un país como Colombia, aquello que debe contarse se vuelve una obligación. El artista asume una postura estético-política y se ubica en un espacio de discordia, de resistencia, buscando generar un conocimiento que conduce a una reflexión, una huella indeleble en la memoria. Es aquí donde la fragilidad de la imagen se pone a prueba.

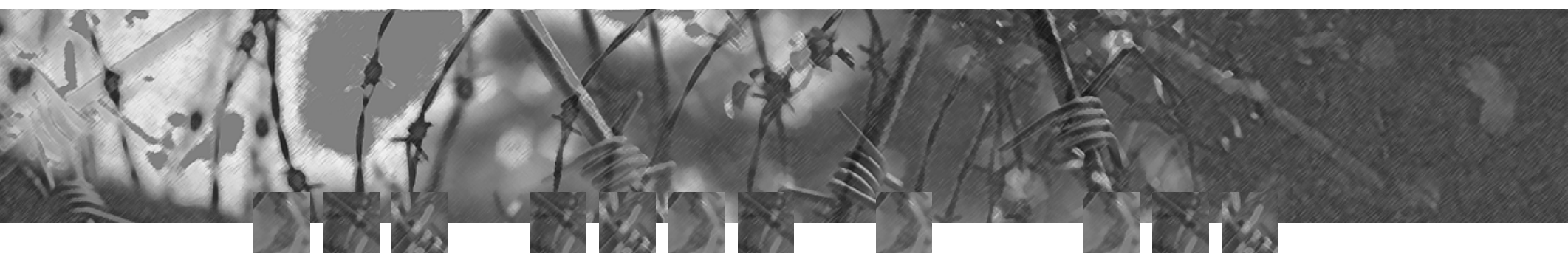




\section{DK: ¿Cuáles son las fuentes de referencia para tu trabajo?}

CR: Mi trabajo no surge de fuentes teóricas, artísticas o filosóficas precisas. Yo diría que, al contrario, cada una de mis películas me ha guiado a referencias impuestas por el tema que abordan. Quiero decir que cada película absorbe más o menos la influencia de ciertas obras y de ciertos autores, sin que haya un corpus teórico o artístico constante. Mi película La impresión de una guerra me condujo por ejemplo a consultar una bibliografía sobre la historia de la violencia en Medellín y en Colombia que sin duda no hubiera leído si no hubiese sentido la necesidad de hacer dicha película. Algunos de esos textos son el libro de Gérard Martin sobre Medellín 1975 - 2013, y los libros del Grupo Nacional de Memoria Histórica, con sus esfuerzos invaluables de reconstrucción de la memoria histórica del país.

En cuanto a las fuentes artísticas, la mayoría provienen de la pintura, arte en el que intenté formarme. Durante mis estudios en pintura me interesé mucho por la perspectiva, sin intentar por ello ser un pintor figurativo. Sentía que la perspectiva ofrecía no solamente una herramienta para la construcción de la representación, sino, más aún, una herramienta para cuestionar la idea de representación. Considero que mis películas nacen todas de ese cuestionamiento, de las implicaciones simbólicas del punto de vista y de la ilusión del espacio.

Durante mi formación de pintor, mis influencias provenían de tendencias abstractas totalmente opuestas a la perspectiva, como el "Hard edge painting", el "Color field painting", el "Support surface" o las pinturas de Simon Hantai. Tendencias que evidencian una negación de la idea de profundidad y de ilusión de tridimensionalidad de la perspectiva. Así que como pintor me sentía acorralado entre dos mundos que no conseguía reconciliar.

Dejé entonces de pintar durante años, hasta que un día me compré una cámara Super8 con la que filmé Tropic Pocket. Ahí me di cuenta de que intuitivamente era capaz de reunir de forma eficaz en el cine las contradicciones que me impedían avanzar en la pintura. La utilización de diferentes archivos visuales en esta pequeña película aborda sin duda la cuestión de la construcción del punto de vista, del orden simbólico del espacio y del tiempo, a partir de un trabajo de materiales y de texturas.

Cuando por fin mi trabajo dejó de ser conflictivo, conseguí disfrutar plenamente de muchas fuentes artísticas que ahora utilizo o intento utilizar. Pinturas de Edvard Munch como Meurtre sur la route (1919) o Le Meurtrier (1910) me sugieren encuadres cinematográficos. L'apparition de St. François à Arlès (1428), de Fra Angélico, es para mí un reto sobre la manera de resolver una acción de grupo en un espacio. Hay también otro tipo de influencias artísticas que no busco traducir cinematográficamente y que son tal vez las fundamentales. El artista autodidacta James Castle por ejemplo. Sordomudo de nacimiento, Castle dibujaba con cuanto cayera en sus manos. Mucha gente le atribuye la mirada "ingenua" del mundo, como la figura del Loco o del 
Idiota en la literatura clásica, el cual termina señalando un camino obvio pero que nuestra ceguera (léase: nuestros paradigmas) nos impide ver. Por mi cuenta, no sé bien cómo definir a Castle, pero sé que sus obras alimentan algo importante en mí.

Para responder plenamente a la pregunta sobre mis influencias, debo hablar también un poco sobre la literatura. No es que sea un gran lector, pero algunos libros me han marcado. Anoto sólo las leyendas de Coyote, figura de la mitología de los indígenas de América del Norte. Coyote es quien enseña el bien haciendo el mal, es el error ejemplar. Vinculándolo al cine, la cuestión moral que coyote plantea es una gran preocupación del documentalista.

DK: El documental ha logrado transgredir el lenguaje cinematográfico, manteniendo una relación estrecha con lo real-como dice Rancière (2005), "lo real no es un efecto que producir, sino un dato que comprender" (p.182-183)- y la ficción -"todo el cine es ficción, cine de la subjetividad” (p.182-183)-. En este sentido, ¿qué es para vos el documental?

CR: Creo recordar que en alguno de sus libros Rancière diferencia el documental y la ficción a partir del efecto de recepción que cada género ejerce sobre el público. El trabajo de la ficción es suspender durante la duración de la película la posibilidad de diferenciar entre realidad e irrealidad. El espectador de ficción acepta obviar la realidad en provecho de la ilusión. El espectador del documental parte al contrario de la certeza de que lo que verá corresponderá exactamente a la realidad. Más aún, cualquier infiltración de irrealidad genera una sospecha del espectador frente a la veracidad del documental. Creo entonces que cuando Rancière habla de "efecto" en su cita, de un efecto que se produce, habla de todo el cine en general como producto de un sujeto que orienta la mirada de un espectador. El cine es un punto de vista, y como tal la expresión de una subjetividad.

Este planteamiento desencaja por supuesto con la idea del documental como espejo de la realidad. Sin embargo, la relación supuestamente "estrecha" entre documental y realidad ha sido frágil desde el principio del cine. Basta con pensar que la segunda versión de La salida de la fábrica Lumière (1895) fue filmada un domingo, día de descanso de los obreros. Chris Marker en Lettre de Sibérie (1957) pone magníficamente de manifiesto la distancia entre lo que se afirma y lo que existe en realidad. El documental sería entonces un cine de la afirmación y no de la realidad. Mientras que la ficción sería un cine de lo posible, de aquello que el espectador puede concebir como posible, así sea por un espacio de tiempo muy limitado.

Yo diría que el documental más que ocuparse de la realidad se ocupa de lo verídico. Lo verídico guarda etimológicamente relación con lo verificable y con la verdad. Lo verificable y la verdad son temas propios a la justicia, y en ese sentido pueden someterse a dudas, ser rebatidos por nuevas verificaciones y nuevas verdades. Como 
le tengo aprecio al cine de Jean Rouch, pienso que para salir del término de cine documental utilizó - quizás muy ingenuamente- el muy controvertido "Cinéma vérité". Retomando ese termino, quisiera entender yo también el documental como un cine de la verdad. Y esa verdad la defino como la certeza de que lo que vemos se nos presenta de una determinada manera que nos parece justa en el momento, sin pensar que sea justa eternamente. Precisamente una verdad que llama a su verificación.

\section{DK: Los documentalistas buscamos acercarnos a determinadas verdades} y compartirlas. ¿Para vos qué es la verdad?

CR: Como lo mencionaba antes, es útil entender la definición de la verdad desde las raíces de la palabra. Verdad, verosímil y verificación son hermanas. De allí resulta que la verdad es algo que se acomoda a una cierta idea que nos hacemos de la realidad. Esta adecuación es un proceso constante, como lo demuestra el trabajo científico. La verdad es constantemente sometida al rigor de la verificación. En el arte, la noción de verosímil se impuso sobre aquella de verdad. La verdad necesita pruebas, lo verosímil se sirve de la persuasión o de la ilusión. La perspectiva es un gran ejemplo de ello. El trabajo del documentalista se plantea entonces en la tensión inherente a todas estas definiciones. El documentalista trabaja entre pruebas, verificaciones, ilusión y persuasión.

DK: Didi-Huberman, en su ensayo Harun Farocki. Against What? Against Whom (citado en Farocki, 2013), dice:

No existe una sola imagen que no implique, simultáneamente, miradas, gestos y pensamientos. Dependiendo de la situación, las miradas pueden ser ciegas o penetrantes; los gestos brutales o delicados; los pensamientos inadecuados o sublimes. No existe una imagen que sea pura visión, absoluto pensamiento o simple manipulación. (p.13)

\section{¿Qué es la imagen y cómo la articulas en tu trabajo?}

CR: La imagen en su sentido más clásico se entiende como un substituto de la realidad, como una pérdida, un duelo frente a lo real. Es el gran mito del dibujo que suplanta al amante que ha de partir. Junto a esta idea de pérdida coexiste la idea opuesta de ganancia: la imagen prolonga aquella realidad que desaparece o que no puede estar por todas partes. El gran ejemplo de esta prolongación es la imagen del monarca, que prolonga su poder a través de su imagen. La imagen siendo más la extensión de su cuerpo político que de su cuerpo físico. La imagen establece entonces una relación ambigua con lo real, a veces de pobreza, otras de abundancia.

La imagen es pobre frente a la realidad en la medida en que la realidad se presenta como una reserva inagotable de materia, de la que la imagen extrae una tajada. El trabajo de reproducción de la imagen es, en ese sentido, siempre imperfecto. Sin embargo, 
la actividad imaginaria de la imagen es mucho más importante que su actividad reproductora. La imagen posee entonces la capacidad de referirse a su modelo señalando al mismo tiempo la distancia que lo separa de él. Así, la imagen es una ganancia frente a la realidad, un desarrollo crítico y sensorial de la realidad.

Pensando lo dicho dentro de la práctica documental, me parece entonces que el documentalista no debe olvidar que su trabajo aparece al espectador en la ausencia de lo que se le muestra. El documentalista no debe intentar remplazar la realidad que escapa al espectador, sino dar la medida de la distancia que separa esa realidad de la imagen que la representa. Esta es sin duda una descripción del trabajo del documental viciada por mi mirada de pintor. El trabajo "pictórico" no es un trabajo del "qué" pero si del "cómo" se representa. Por ejemplo, no es por un capricho que yo trabajo en celuloide en una época en la que predomina la imagen numérica. La presencia material del celuloide imprime a mis imágenes una des-semejanza con respecto a los cánones de representación realista. La hiper-difusión, la instantaneidad de la imagen numérica, la posibilidad de ser creada enteramente de manera artificial, tienden a producir un efecto de realidad que intenta hacernos olvidar la distancia frente al objeto real. En tal contexto, las imágenes no permiten que el espectador sea suficientemente crítico frente a ellas y las evalúe como lo que son: imágenes y no realidades. Yo no trabajo entonces en la nostalgia del celuloide, pero sí en la distancia que éste me permite con respecto al mundo en el que vivo, en respuesta a este mundo.

Volviendo a lo que sería mi definición de la imagen, me gustaría mencionar un párrafo que debía comenzar La impresión de una guerra, pero que finalmente Sophie (mi compañera y co-guionista) y yo terminamos descartando: Si la imagen de un río es la metáfora por excelencia del tiempo, la imagen fija de un río sería la metáfora de la memoria, cuyo trabajo es intentar fijar un material fluido. Pienso que ilustra nuestra conciencia de que abordábamos un trabajo que relacionaba la imagen a la memoria.

DK: En Tropic Poket combinas tus imágenes hechas en el Chocó con found footage. ¿Cómo funciona el relato documental en ese proceso de re-escritura?

CR: El found-footage es un golpe de suerte. Vas investigando en una dirección y de repente te topas con una fuente inesperada. Pero no hay suerte que no se merezca, que no se trabaje. El pedazo de película que encuentras es una tajada de un espacio y de un tiempo que hay que interrogar. Aparece como un vestigio en más o menos buen estado de una situación que vas a intentar entender manipulando las imágenes. Es como un edificio inestable con partes que faltan. Ciertos autores intentan subsanar esos vacíos, completarlos con un discurso que dé cuenta de ellos. Yo prefiero entrar 
al edificio por los huecos, y una vez adentro derrumbar paredes si me encuentro aprisionado. Quiero decir, con esta metáfora barata, que mi trabajo con el archivo es material, se hace con herramientas (corte, pega, superposición...).

DK: Hablame sobre el tiempo, la continuidad y el trance en el trabajo de Tropic Pocket.

CR: Tropic Pocket fue mostrada en Francia por primera vez en el Musée du Quai Branly, "El museo de arte primitivo". Después de la proyección siguió una charla con el antropólogo Patrick Deshayes, quien trabajó con la tribu Huni Kuin de la Amazonía. Deshayes explicó que para los Huni Kuin la continuidad y la discontinuidad del tiempo eran ideas que diferenciaban al sueño y al trance de la realidad. Para los Huni Kuin, la realidad se presenta como un encadenamiento de eventos dentro de una continuidad, mientras que el sueño y el trance se presentan bajo la forma de fragmentos de eventos y de imágenes. Interpretar el carácter aparentemente arbitrario con el que se encadenan los fragmentos es una de las bases del conocimiento de los Huni Kuin. Patrick Deshayes convocó a la charla estas ideas para pensar Tropic Pocket como un encadenamiento de fragmentos dispuestos para ser interpretados, $\mathrm{y}$, de manera general, toda creación cinematográfica.
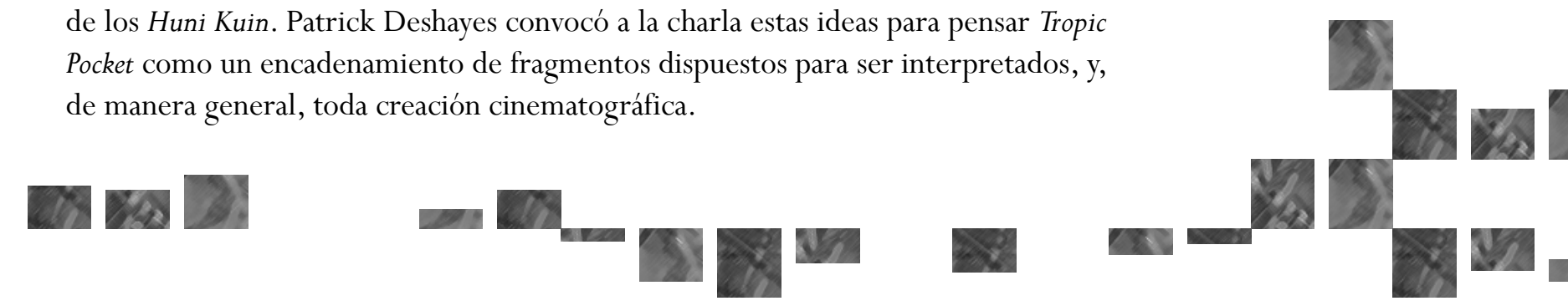

DK: ¿Cómo trabajas la materialidad del cine frente a la materialidad de la realidad? Tomemos como referencia tu trabajo Como crece la sombra cuando el sol declina.

CR: El punto de partida de la película era acercar los gestos circulares y cíclicos de dos grupos de trabajadores: un grupo de jóvenes subsistiendo con las ganancias de sus espectáculos improvisados en los semáforos, y un grupo de mecánicos que deshuesan los autos fuera de servicio para vender las piezas en buen estado o los materiales al peso. Malabaristas y mecánicos viven de la circulación de los autos, aprovechando sus paradas provisorias en los semáforos, y sus paradas definitivas en la deshuesadora. Es una película sobre aquellos que no avanzan, en donde lo lento y la repetición se oponen a la velocidad.

A medida que iba filmando, fui comprendiendo que otra oposición surgía: el trabajo manual contra la máquina. Esta oposición resonaba con mi propia práctica de cineasta, privilegiando la utilización de la película, que yo mismo revelo, corto y pego en el laboratorio asociativo L'Abominable. Hasta los archivos de YouTube los paso a $16 \mathrm{~mm}$. Filmándolos me los apropio. Siento que los entiendo mejor cuando los miro a través de la cámara y no como espectador frente a un computador. Paso así del rol pasivo del espectador al papel activo del camarógrafo. Por supuesto distorsiono el archivo. 
Pero ya dije más arriba -hablando sobre la imagen- que, formado en la pintura, las múltiples distancias frente a lo real son para mí importantes.

DK: ¿Cómo utilizas tu voz frente a la voz de los otros (alguna vez has hablado de distanciamiento)?

CR: Para retomar lo que he dicho con respecto a la pintura, considero que mi voz aparece como aquello que enmarca una situación. Es decir que hasta ahora la he utilizado para delimitar las fronteras entre un contexto y otro, un cuadro y otro. En mis cortometrajes se tejen generalmente lazos entre varias historias y varios personajes. Mi aparición me sirve como una herramienta para pasar de una a otra.

La noción de distanciamiento no sé si sea pertinente para señalar mi intervención con la voz. Al elegir el marco de la historia intento por supuesto crear una mirada crítica que pueda poner en evidencia lo que cada testimonio o fuente no revela enteramente.

La aparición de mi voz en las películas llegó tras múltiples intentos de dejar hablar las imágenes por sí mismas. Intentos en los que fallé de diferentes maneras. La voz off es un recurso muy clásico del cine documental, casi despreciado actualmente como una facilidad. Pero por más que le diera vueltas, siempre pensaba en lo fantástico que era escuchar o leer a los personajes de Thomas Berhard en sus cavilaciones, a los detectives de las novelas de série noire, a las introducciones de Van der Keuken en sus películas. Así que, pues ni modo, la adopté.

DK: En tu obra hay una clara propuesta experimental, del disenso según yo; otros lo han denominado "Documental Punk". En ese espacio, ¿qué significa tener lo real como materia prima de tu creación?

CR: ¿Qué es lo real para una cámara? Para mí lo real en cine es lo que surge cuando uno trabaja la materia con una herramienta. La cámara es esa herramienta. Quiero decir que el cine no solo crea imágenes, sino que moldea una realidad.

Lo de documental "Punk" no sé bien a quién se le ocurrió como denominación. No es del todo inapropiado si se piensa que yo trabajo con mucha energía en un espacio muy reducido, como un grupo que ensaya en un garaje. La impresión de una guerra es una película hecha con rabia, y esa rabia es perceptible. Yo no intento una imparcialidad en el documental. Mi punto de vista es bastante subjetivo, se alimenta de sensaciones y de emociones. En La impresión de una guerra, como en Tropic Pocket, muestro que me siento engañado, que puedo engañar, que soy sincero, que estoy confuso pero que debo ir. "Don't know what I want but I know where to get it", una frase de los Sex Pistols que me cae perfecta. Creo que es así como yo trabajo, sin saber qué es lo que voy a conseguir, pero sabiendo para dónde ir. 
DK: A través del arte a veces se busca "la expresión de lo siniestro" que hay en el alma humana, según el cineasta Óscar Campo. Yo veo algo de eso en Impresión de una guerra. ¿Cómo enuncias lo siniestro en tu obra?

CR: Para mí lo siniestro no es una intención, sino un síntoma. Yo no lo busco, pero aparece como un sudor del contexto en el que filmo. Lo siniestro es algo de lo que intento huir pero que no sé de qué manera termina apareciendo. Claro, La impresión de una guerra es una película terrible porque busca las pistas de la violencia en la cotidianidad y en lo banal. Pero hay que enmarcarla en el contexto colombiano que nos correspondió a mi generación, a la generación de mis padres y abuelos. Conocimos una época en la que atravesar un puente, tomar un taxi, ir a una fiesta, podían convertirse en un hecho funesto. Aunque hubiéramos atravesado muchos puentes, tomado muchos taxis o ido a muchas fiestas, siempre "ficcionalizábamos" ese último puente, taxi o fiesta. Todo el mundo estaba constantemente imaginando lo peor.

Como resultado, los hechos reales se sobredimensionaban en el imaginario, se transponían a todas las situaciones. Estábamos sumergidos en lo real -de por sí bastante siniestro- y en la ficción de ese real -a veces aún más siniestra-. Creo que esa es una de las razones por las que decidí salir de Colombia. Ya estaba hasta el tope de imaginar situaciones "últimas" y de escuchar las situaciones "últimas" imaginadas por los otros.

\section{DK: ¿Cuál es la propuesta política que haces a través de tu arte?}

CR: Ninguna. No considero que el arte pueda suplantar una decisión política, aspirar al mismo impacto. Considero la mayoría de las intervenciones "políticoartísticas" como ingenuas, y tal vez egocéntricas. Los talleres artísticos dirigidos a despertar "la conciencia política de la población" me parecen un producto panfletista. Aunque debo decir que existen intervenciones eficaces. En La impresión de una guerra mencioné el trabajo del colectivo Toque de queda. Una movilización que puso en suspenso tanto a las autoridades como a las bandas barriales, señalando una situación supuestamente "invisible" que afectaba a un gran número de ciudadanos.

DK: Abordemos de nuevo el tema de la perspectiva, pero esta vez enfocada en la violencia en Colombia. ¿Cómo funciona en tu cinematografía?

CR: Retomamos la palabra "perspectiva" de la que ya he hablado. La perspectiva es un orden simbólico dentro de un tejido espacial que ahora concebimos también como orden histórico. Panofsky mostró en qué medida la perspectiva no es solamente un problema matemático o técnico, sino que, 
más aún, es un factor de orden del mundo desde una posición determinada del sujeto. Este orden no para de transformarse. De ahí que Panofsky se detenga en la descripción de las múltiples formas de perspectiva, y en los contextos intelectuales, religiosos y sociales que contribuyeron a su surgimiento. ¿Cómo entonces poner en perspectiva la historia de la violencia en Colombia? ¿A partir de qué punto de vista se organiza la visión del conflicto? ¿De qué manera esta visión debe ordenarse frente al espectador? ¿Cuál es el punto central que ordena esta visión? La impresión de una guerra comienza respondiendo a esta última pregunta: no existe un relato unificador capaz de justificar el conflicto. Los múltiples actores han expandido todas las razones lógicas que podrían dar cuenta del porqué de la violencia. Sin un punto central que ordene el discurso (o la visión de la violencia), se abre el camino a múltiples puntos de fuga. Todo el trabajo de La impresión de una guerra es seguir las líneas que pueden trazarse a partir de esos puntos.

La visión del conflicto no se organiza entonces desde una sola perspectiva histórica. Por ejemplo, en La impresión de una guerra yo digo que el conflicto armado contemporáneo data de más de 70 años, mientras que muchos historiadores lo datan de menos tiempo. Siempre esperé confrontarme a alguien que rebatiera mi datación... Si yo afirmo esto es porque estoy cortando el espacio simbólico del conflicto de una manera no convencional. Estoy intentando darle un marco histórico desde otra perspectiva. La idea de un discurso unificador de la guerra es una herramienta de poder que utilizan los medios de comunicación, los políticos, los militares, los grupos rebeldes. Decir: "el problema son las FARC", equivale a decir "la supresión de las FARC es la supresión del problema". Un espejismo. Digo las FARC pero se adapta a cualquier actor, sin olvidar "La corrupción". Volvemos entonces a la cuestión de la instrumentalización de los discursos, de las obras.

Tomando el partido de las fugas, y no del punto central, mi trabajo intenta escapar a cualquier ideología, se vuelve irrecuperable para cualquier campo. Esto es fácil porque lo que yo hago es interrogar el material que encuentro, interrogarme yo mismo frente a las pistas que sigo; y de ninguna manera avanzar hacia una explicación. Lo que decía Pedro Adrián Zuluaga sobre la novela policial según Piglia me parece extremamente excitante como método: el inspector que sigue las huellas para llegar a la pregunta y no a la respuesta.

DK: Tras haber vivido la mitad de tu vida fuera de Colombia, ¿cómo conectas con tu país desde la distancia? Tu obra plantea aspectos diferentes a los de los artistas colombianos que viven la violencia y la guerra desde el interior, ¿qué ves vos que no ven ellos?, ¿qué ven ellos que no ves vos?

CR: Mi relación a distancia con Colombia es una pregunta que me hacen a menudo. Esta es la respuesta que siempre doy: viví en Colombia hasta los 22 años. Desde entonces los recuerdos, las conversaciones telefónicas y las informaciones de los 
medios de comunicación se han substituido a la experiencia cotidiana del país. Progresivamente, un país diferente de aquel que conocí ha tomado forma para mí. Esta Colombia restituida en mi imaginario la confronto en ocasiones a la realidad del país. Así, durante estadías puntales comencé a hacer mis películas. Es tal vez por esta razón que el destino de las imágenes, los diferentes estratos de la representación de un territorio, son cuestiones que interrogo en cada uno de mis trabajos en Colombia.

Ahora intento ampliar mi mirada sobre Colombia a un contexto mayor. Viviendo en Francia, he tenido la oportunidad de cruzarme con personas cuyas experiencias de vida resuenan con las mías. Mi último cortometraje (mi primera ficción) acontece en un espacio simbólico y mental que trasciende las fronteras de un país, de una cultura. Ha sido rodado con músicos de la Reunión, pero de alguna manera creo haber logrado un cruce entre las Antillas, el Caribe y las islas cercanas al canal de Mozambique.

DK: El análisis de una película debe ligarse a la experiencia personal del autor, por eso me interesa preguntarte: ¿cuál es tu relación con la violencia?

CR: Me gustaría evitar ese pensamiento común que considera que el haber experimentado la violencia valida el interés en el tema. Un pensamiento que se aplica a todo nivel de manera automática y reductiva: solo los pobres saben de la pobreza, solo las víctimas saben de la violencia, etc. La experiencia de la violencia es en primer lugar una experiencia subjetiva, que no es comparable de una persona a otra. El sentimiento de ser víctima es un afecto intensivo a grados diferentes según las personalidades (dos personas quedan afectadas de manera diferente frente a un mismo acto violento). El marco jurídico, la justicia, es el paso siguiente para considerar si de manera objetiva un tipo de agresión puede clasificarse como delito, estipulando así quién es víctima y quién victimario. Que yo mismo me reconozca como víctima de una agresión, o como victimario, no debería tener ningún impacto en mi trabajo. Pero como sé que sí lo va a tener, pues recuso expresarme en ese sentido. Recuerda que en la Ley de Víctimas se ha escrito claramente que el estado reconoce el estatuto de víctima a la sociedad colombiana en su conjunto.

\section{DK: ¿Qué lugar ocupa el artista en la construcción de memoria?}

CR: Abundan los discursos en los que se dice que la memoria es reconstrucción. Un acto creativo. Como acto creativo pasa por mecanismos de percepción, selección, jerarquía de contenidos, olvidos, remplazos. La memoria es también un acto de 


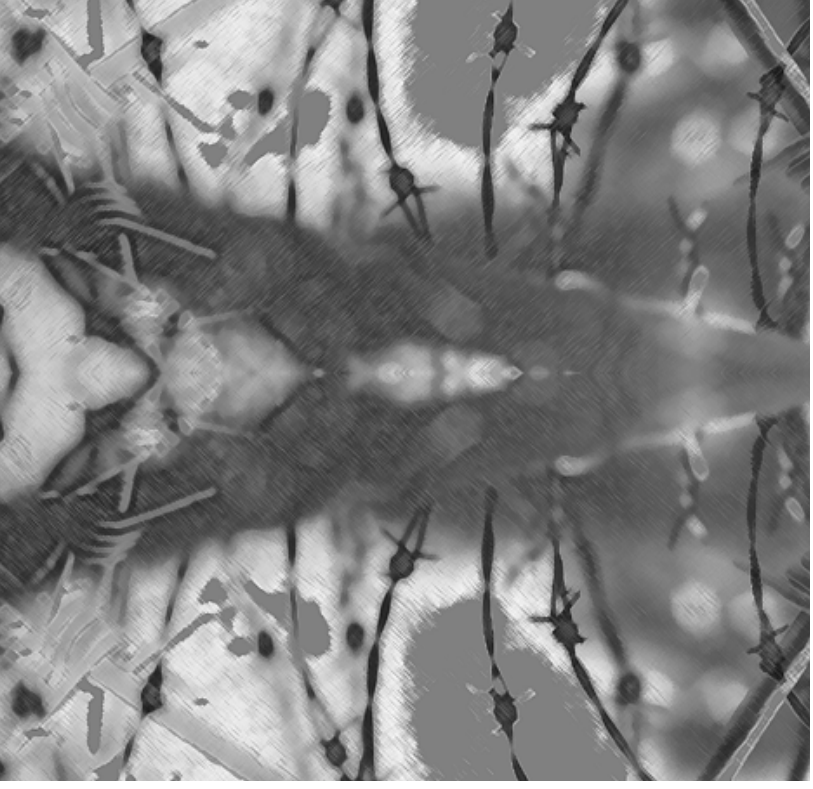

construcción: define la identidad de un individuo y de una sociedad. ¿Cómo hacer que esa reconstrucción-construcción no sea un acto automático, un dato, sino por el contrario una labor consciente? Es en esa consciencia en donde el acto creativo se ejerce plenamente.

DK: Farocki, en Fuego inextinguible (1969), trabajaba con estas preguntas en mente: “¿Cómo impartir conocimiento en alguien que se niega a conocer? ¿Cómo abrir los ojos?”·¿Qué papel juega el espectador en tu proceso creativo?

CR: En Fuego inextinguible Farocki se quema el brazo evocando una pedagogía de la experiencia. Años más tarde, su trabajo se aventura en el dominio de la imagen, en un laberinto de espejos en el que la experiencia y la pedagogía se confunden con lo virtual y lo lúdico. How to live in the FRG (1990) o Serious games (2016) son en ese sentido películas edificantes en donde la experiencia cede su lugar a la puesta en escena y a la realidad virtual, en donde el aprendizaje (o el des-aprendizaje de la guerra) se confunden con el juego.

La respuesta a la pregunta “¿cómo abrir los ojos?” Farocki mismo la da en Respite (2007): observando. Zoom, agrandamiento, imagen congelada, todo un arsenal de herramientas para observar algo que creemos haber ya visto. Creo que, entre Fuego inextinguible y Respite, Farocki pasa de la demostración a la "mostración” como método. En este último método quisiera incluirme.

DK: Hay directores que esperan que sus películas no sean "instrumentalizadas" ni por lo comercial, ni por nada, sino que sean un ejercicio de creación. ¿Qué piensas acerca de esto? ¿Qué finalidad tienen tus películas?

CR: La cuestión de la instrumentalización del trabajo artístico escapa la mayor parte de las veces al autor. La denominación "Arte degenerado" que condenó a las Vanguardias durante la Alemania Nazi es un gran ejemplo de la instrumentalización del arte muy a pesar de los artistas. Condenar un trabajo puede resultar entonces tan panfletista como enaltecerlo.

En mi caso concreto, me gustaría ilustrar esta cuestión con las fuentes que sirvieron a la realización de Tropic Pocket: un anuncio publicitario de la marca Chevrolet, una película de los evangelizadores Claretianos, una serie de videos de militares del Ejército y de combatientes de grupos rebeldes. El denominador común de estas fuentes es ser todas vehículos de ideologías colonizadoras. Me pareció inútil agregar, por la denuncia, una tensión más en el juego de fuerzas operando allí. Mi ambición en Tropic Pocket era proponer un mapa imaginario de la zona, capaz de liberarse de 
los marcos impuestos. Para ello, mi solución fue operar por medio de los elementos propios del cine (montaje, narración) una "des-instrumentalización” de esas fuentes, intentando un "distanciamiento" crítico, en el sentido de Bertolt Brecht.

Retomando tu pregunta sobre la finalidad de mis películas, creo que está ligada a la idea de la posibilidad de crear una mirada crítica al respecto de una situación. Yo diría -honestamente- que comencé haciéndolas para forjarme yo mismo esa mirada. No se me ocurrió de ninguna manera crear un discurso mesiánico del tipo: les voy a revelar la realidad. Aunque tampoco creí que el ejercicio de creación se justificara en sí mismo (lo que señalas en la pregunta).

El hecho de que mis trabajos tengan ahora un público es algo bastante reciente. De allí intuyo que mi finalidad primera -forjarme un punto de vista- repercute en otros, se propaga como un eco. Sin duda porque somos muchos quienes queremos entender el contexto en el que vivimos, y que nos ayuda ver cómo lo entienden los otros.

DK: Intuyo que la producción de tus películas es marginal, ¿cómo funciona?

CR: Completamente de acuerdo contigo. Las películas son también marginales en su producción. En primer lugar porque los fondos de subvención constituyen grupos de evaluación de expertos que privilegian un tipo de miradas. Expertos que prolongan sus propias prácticas e ideas: productores, realizadores, programadores, televisiones, que ya han sido validados por el sistema y que validan a su vez el sistema que los validó.

Segundo, porque una obra se piensa desde las capacidades de financiación. Todo está supeditado a lo que se puede pagar o conseguir sin pagar. Por ejemplo, ¿se puede pagar un técnico de sonido en el rodaje? Si no se puede hay que tener en cuenta que el sonido es de mala calidad, o desincronizado, o una voz de postproducción cubre otra para palear alguna carencia. Este último ejemplo es lo que sucedió con la voz de Pastora Mira al final de La impresión de una guerra. ¿Se puede pagar una película nueva, un revelado en laboratorio? No. ¿Entonces filmar en video? No, entonces filmar con películas viejas regaladas o compradas a bajo precio... Son aspectos técnicos que terminan siendo aspectos formales, y que a su vez traducen las operaciones de inteligencia del realizador al construir su discurso, su método de trabajo, su elección en los contenidos. En tercer lugar, porque los tiempos de los fondos de producción no corresponden a las urgencias del realizador frente a una realidad inestable. En el caso de un cine hecho con personas y no con actores, a veces no se puede esperar a tener dinero.Y, en cuarto lugar, porque decidir sobre la independencia económica es tener la libertad de crear sus propias estrategias creativas de producción, desarrollo y distribución. 
Para dar un ejemplo concreto, La impresión de una guerra no recibió ninguna ayuda económica, no pasó los criterios de ningún fondo de ayuda (aunque no me presenté a muchos, la verdad). Se hizo en tres años durante el período de vacaciones en que iba con mi esposa y mi hijo a visitar a mis padres. Comenzó entonces como un proyecto personal, paciente, y sin ninguna expectativa. Una empresa de familia, en la que el apoyo de mi esposa (Sophie Zuber) fue fundamental en la escritura y el rodaje. Íbamos atando los cabos después de cada viaje, mirando las imágenes y pensando las que necesitaríamos hacer el año próximo en las vacaciones siguientes. No es una película marginal, es más bien una película vacacional. Una película de amateur más que una película de profesionales. Se rodaron solamente 90 minutos de imágenes para un resultado de 26 después del montaje. Quiere decir que las maneras de producción precaria pueden tener un impacto positivo. Aunque, pasa siempre, me pasa ahora, los fondos de ayuda pueden tomar el atajo simplista de decir: usted no necesita dinero porque se defiende muy bien sin nada. Lo que quiere decir que los fondos pueden mantenerte en el mismo status quo, impidiéndote pensar un cine más ambicioso. Pensamiento estúpido como aquel que dice: los pobres no necesitan nada porque mire cómo viven de felices y cómo son de ingeniosos para sobrevivir.

\section{DK: ¿Cómo los conceptos de civilización y barbarie están articulados en tu obra?}

CR: De cierta manera, una película como La impresión de una guerra intenta trazar el tejido de civilización dentro de la barbarie expuesta en las marcas de la guerra. El análisis (el mapa puesto en escena por las imágenes y los textos) intenta un contrapunto a esa barbarie. La barbarie sería entonces la proliferación desordenada de marcas y actos que demuestran una deshumanización de los actores de la guerra. La civilización, en un sentido muy amplio, correspondería a la definición de las estructuras que delimitan una sociedad dentro de su producción de marcas (valores, creencias...). La impresión de una guerra es de alguna manera una invitación a reflexionar (a crear civilización) sobre el tipo de sociedad que se construye a partir de esas marcas.

No sé, sin embargo, si esta definición se puede adaptar a todas mis películas. Pensando en barbarie se llega a la idea de un modo de actuar sin límites ni principios. Según eso, yo creo que hago un cine bárbaro en el sentido de que no parto de un principio de orden, de un texto o de una idea capaz de edificar claramente el rumbo de la película. Tropic Pocket o Como crece la sombra cuando el sol declina son películas salvajes, es decir hechas de manera muy intuitiva. Me pregunto si en todas ellas no hay una cierta violencia del material, desde la construcción y la imagen misma del $16 \mathrm{~mm} . .$. ¿Pero violencia y barbarie pueden ser sinónimos? Tal vez no...

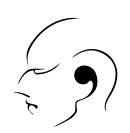




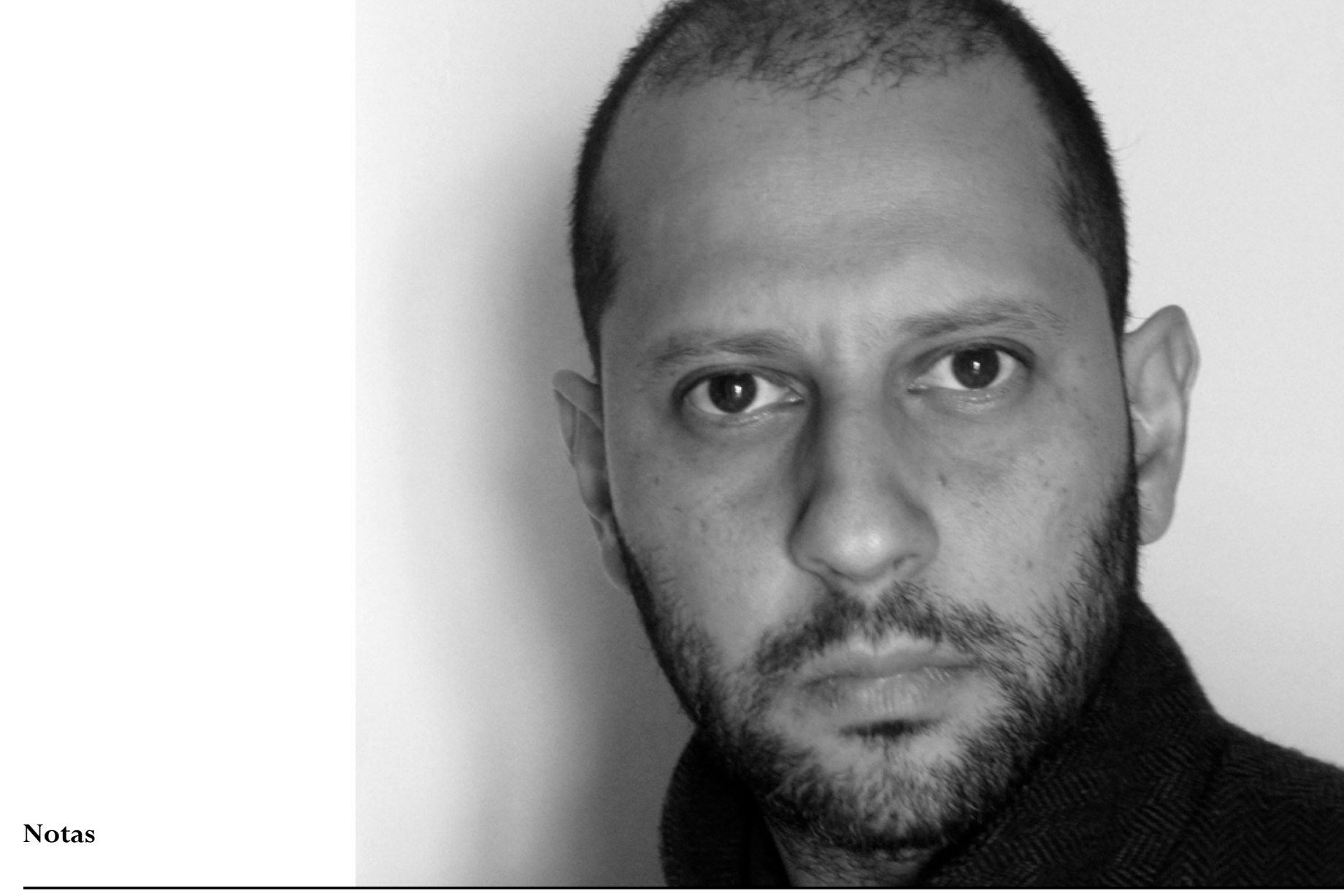

${ }^{1}$ Docente titular de la Escuela de Comunicación de la Universidad del Valle, Doctora en Investigación en medios de comunicación (Universidad Carlos III de Madrid), Maestra en Comunicación y Cultura (Universidad Federal de Rio de Janeiro), Máster en Documental de Creación (Universidad Pompeu Fabra de Barcelona).

${ }^{2}$ Pintura de contornos nítidos, es un movimiento pictórico de la pintura abstracta definido por las transiciones abruptas entre las áreas de color, que generalmente son de un solo color invariable.

${ }^{3}$ Pintura de campos de color, estilo de pintura abstracta caracterizado, principalmente, por amplios campos de color liso y sólido, extendidos o teñidos en el lienzo, creando áreas de superficie uniforme y un plano liso de imagen. El movimiento otorga menor énfasis a la pincelada y la acción, a favor de la consistencia de la forma en su conjunto y del proceso.

${ }^{4}$ Movimiento pictórico que no se caracteriza por un estilo particular sino más bien por un planteamiento que concede una importancia igual a los materiales, a los gestos creativos y a la obra acabada.

\section{Referencias}

Kuéllar, D. (2019). Documental del disenso: representación de la violencia contemporánea en Colombia (tesis doctoral). Universidad Carlos III de Madrid, España. Recuperado de https://e-archivo. uc3m.es/handle/10016/29551

Farocki, H. (2013). Desconfiar de las imágenes. Buenos Aires, Argentina: Caja Negra Editora.

Rancière, J. (2005). La fábula cinematográfica: Reflexiones sobre la ficción en el cine. Buenos Aires, Argentina: Ediciones Paidós. 